\title{
Analysis of Kaolinite isomorphic substitution and microstrain in hardsetting soils horizons through X-ray diffraction and the Rietveld Method
}

\author{
${ }^{1}$ Laboratory of Soil Physics and Environmental Sciences, Department of Physics, State University of Ponta Grossa (UEPG), PR, Brazil \\ ${ }^{2}$ Department of Soil Science and Agricultural Engineering, State University of Ponta Grossa (UEPG), Ponta Grossa, PR, Brazil \\ *Email: luisprandel@gmail.com
}

\begin{abstract}
The term hardsetting is used to describe tropical soil horizons, which are highly weathered and present high hardness degree when dry, becoming friable when humid. Some studies revealed that in these soils, the Kaolinite tends to present isomorphic substitutions of $\mathrm{Al}$ by $\mathrm{Fe}$, deforming its crystalline structures. Thus, the objective of this study was to analyze the Kaolinite isomorphic substitution degree in hardsetting through X-ray Diffraction and the Rietveld Method (XRD-RM) and compare it with its microstrain average values and the crystallite average size. Five soils samples were collected in the Brazilian Coastal Tablelands region, dispersed and submitted to the physical fraction separation process. The clay fraction analyses were carried out in a diffractometer XRD Rigaku, model Ultima $\mathrm{IV}$, with $\mathrm{CuK}_{\alpha}$ radiation, step by step mode in the $5^{\circ} \leq \mathbf{2 \theta} \leq \mathbf{8 0}^{\circ}$ $\left(0.02^{\circ} / 5 \mathrm{~s}\right)$ and refined through the RM using GSAS+EXPGUI. Results revealed that Kaolinites with the highest microstrain values were those that presented higher degree of isomorphic substitution. Based on these results, it is possible to state that soils with higher degrees of isomorphic substitutions probably corroborate to hardness degree, due to the charge excess between the Kaolinite layers.
\end{abstract}

Index Terms - Crystallite size; GSAS; Clay

\section{INTRODUCTION}

$\mathrm{T}$ HE term hardsetting is used to describe tropical soil horizons, which are highly weathered and present high hardness degree when dry, becoming friable when humid [1].

Some studies revealed that these soils present high Kaolinite content in the clay fraction and due to the high weathering degree, the Kaolinite tends to present isomorphic substitutions, in which $\mathrm{Fe}$ atoms substitute $\mathrm{Al}$ in their octahedral sites [2]. These substitutions affect significantly the
Kaolinite unit cell parameters, deforming its crystalline structures [3]. This can be seen in clays hardsetting horizons using the techniques of X-ray Diffraction (XRD) and Rietveld Method (RM) [4].

Thus, the objective of this research was to analyze the Kaolinite isomorphic substitution degree in hardsettings through XRD-RM and compare it with its microstrain average values (or crystallite average size).

\section{Materials AND MethodS}

\section{A. Samples}

Five hardsetting samples were collected in the Brazilian Coastal Tablelands region: (1), (3) and (4) Yellow Ultisol (Argisol); (2) Yellow Oxisol (Latosol); and (5) Gray Ultisol. All samples were dispersed in ultrasound and $\mathrm{NaOH}$ solution, submitted to the physical fraction separation process (clay, silt and sand) through sedimentation, using the Stokes law [4]. Clay fractions were powdered, dried in oven and sieved in a $53 \mu \mathrm{m}$ mesh sieve.

\section{B. Analysis}

The clay fraction analysis were carried out in a diffractometer XRD Rigaku, model Ultima IV, with $\mathrm{CuK} \alpha$ radiation, step by step mode in the $5^{\circ} \leq 2 \theta \leq 80^{\circ}$ band (step $0.02^{\circ} / 5 \mathrm{~s}$ ). This data was obtained by employing the following slits: divergence $1.00^{\circ}$, reception $0.15 \mathrm{~mm}$ and scattering $1.00^{\circ}$.

\section{Rietveld Method}

GSAS [5] and EXPGUI [6] with X-ray powder diffraction data were used for the Rietveld refinement. The Rietveld Method consists in minimizing the difference between the calculated, $y_{c i}$, and observed, $y_{i}$, X-ray powder diffraction, through the least squares method, by minimizing of the equation: 


$$
S_{y}=\sum w_{i}\left(y_{i}-y_{c i}\right)^{2}
$$

where, $w_{i}\left[=\left(1 / y_{i}\right)^{1 / 2}\right]$ is the weight function in the $i$-nth step and $n$ is the total number of steps [7,8].

The Bragg reflections calculated intensities, whose Miller indices $(K)$ related to each crystalline phase $(p)$ are expressed by the Eq. (2) [9]:

$$
y_{c i}=s_{R} \sum_{p} S_{p} A_{p}\left[\sum_{K} L_{K}\left|F_{K}\right|^{2} \phi\left(2 \theta_{i}-2 \theta_{K}\right) a_{K} P_{K}\right]_{p}+y_{b i},
$$

where $s_{R}$ is a function which models the roughness effects on the sample surface; $S_{p}$ and $A_{p}$ are the scale and absorption factors; $L_{K}$ contains the Lorentz factors, polarization and multiplicity; $\phi$ is the diffraction profile function, given by a Modified Pseudo Voigt, $\theta_{i}$ is the scattering angle, and $\theta_{K}$ the Bragg reticular plane diffraction angle; $a_{K}$ is the function that corrects peak asymmetry; $P_{K}$ is the preferential orientation function; $\left|F_{K}\right|^{2}$ is the squared structure factor which is related to each phase crystalline structure; and $y_{b i}$ is the background radiation intensity [9].

To phases index were used the following crystal structures [10]: Kaolinite (Ka) and Halloysite ( $\mathrm{Ha})\left[\mathrm{Al}_{2} \mathrm{Si}_{2} \mathrm{O}_{5}(\mathrm{OH})_{4}\right]$; Goethite (Gt) $[\alpha-\mathrm{FeO}(\mathrm{OH})]$; Anatase (An) and Rutile (Rt) $\left(\mathrm{TiO}_{2}\right)$; Gibbsite (Gb) $\left[\gamma-\mathrm{Al}(\mathrm{OH})_{3}\right]$; Quartz (Qz) $\left(\mathrm{SiO}_{2}\right)$; Calcite $\quad(\mathrm{Ct}) \quad\left(\mathrm{CaCO}_{3}\right) ; \quad$ Muscovite $(\mathrm{Mu})$ $\left[\mathrm{KAl}_{2}\left(\mathrm{Si}_{3} \mathrm{Al}\right) \mathrm{O}_{10}(\mathrm{OH}, \mathrm{F})_{2}\right]$; Hematite $(\mathrm{Hm})\left(\mathrm{Fe}_{2} \mathrm{O}_{3}\right)$.

Microstrain and crystallite size values were obtained from the FWHM for each Kaolinite reflection peak employing Scherrer, and Stokes and Wilson definitions [11].

\section{RESUlts AND DISCUSSIONS}

With the XRD-RM results, show in Fig. 1 and Table I, it was possible to estimate the percentage of material found in the clay fraction, which had Kaolinite as the predominant material.

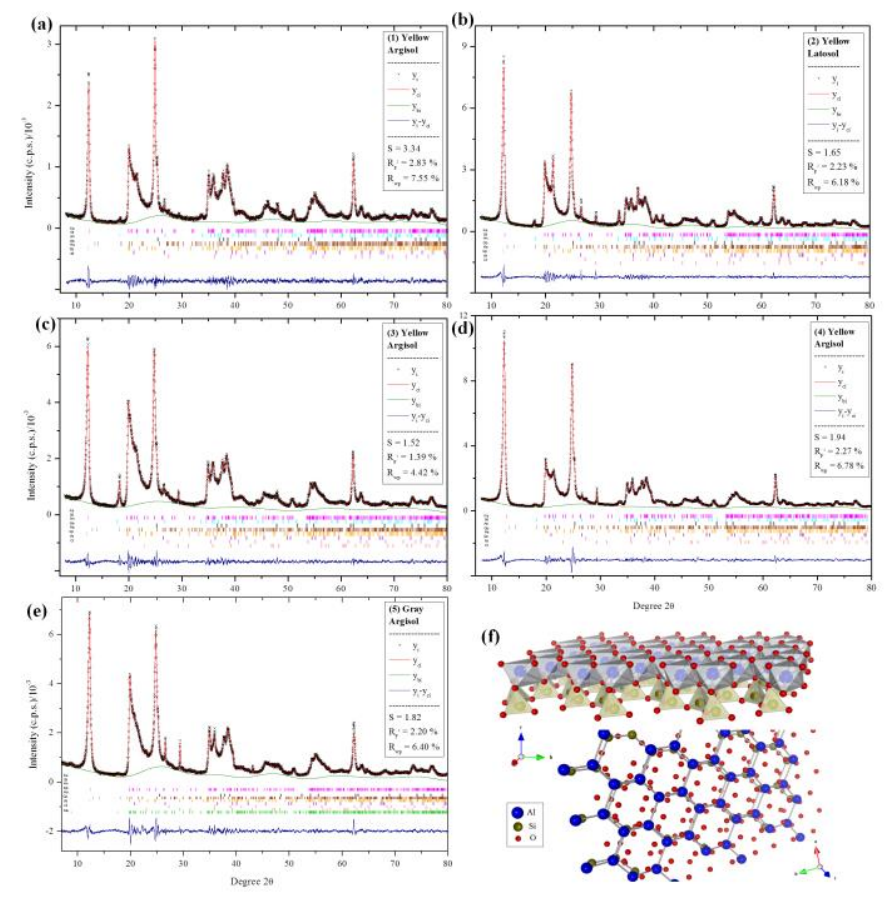

Fig. 1. (a)-(e) Graphs of RM-XRD refinements of clay fractions samples, considering isomorphic substitutions in Halloysite and Kaolinite (Al by Fe) and Goethite (Fe by $\mathrm{Al}$ ). The terms $y_{i}, y_{c i}$ and $y_{b i}$ are the intensities observed, calculated and background radiation, respectively. The vertical lines below the peaks are the reflection of the following minerals: Kaolinite (Ka), Halloysite (Ha), Goethite (Gt), Anatase (An), Rutile (Rt), Gibbsite (Gb) and Quartz (Qz).

Table 1. Minerals percentage of clays in Hardsetting horizons.

\begin{tabular}{llllll}
\hline $\begin{array}{l}\text { Mineral } \\
\text { sample }\end{array}$ & 1 & 2 & 3 & 4 & 5 \\
\hline $\mathrm{Ka}$ & $60.37(8)$ & $57.35(7)$ & $55.35(6)$ & $62.04(6)$ & $64.87(1)$ \\
$\mathrm{Gt}$ & $5.4(1)$ & $10.14(8)$ & $1.90(6)$ & $3.98(7)$ & - \\
$\mathrm{An}$ & $2.67(6)$ & $2.47(7)$ & $2.35(4)$ & $4.43(8)$ & $9.42(8)$ \\
$\mathrm{Gb}$ & $6.7(1)$ & $13.7(1)$ & $13.4(1)$ & $4.9(1)$ & $0.48(8)$ \\
$\mathrm{Ha}$ & $20.9(1)$ & $13.1(1)$ & $24.28(5)$ & $18.5(1)$ & $15.72(8)$ \\
$\mathrm{Qz}$ & $3.17(7)$ & $2.32(4)$ & $1.26(4)$ & $2.21(7)$ & $1.55(4)$ \\
$\mathrm{Rt}$ & $0.80(5)$ & $0.43(3)$ & $0.46(2)$ & $1.96(6)$ & $0.51(1)$ \\
$\mathrm{Ca}$ & - & $0.47(5)$ & $0.77(3)$ & $1.98(5)$ & $1.70(4)$ \\
$\mathrm{Mu}$ & - & - & - & - & $5.8(1)$ \\
\hline
\end{tabular}

With the XRD-RM results, it was possible to estimate the percentage of material found in the clay fraction, which had Kaolinite as the predominant material. Besides Kaolinite, considerable percentage of Halloysite, and small amounts of Goethite, Gibbsite, Anatase and Rutile were found.

Results also revealed that Kaolinites with the highest microstrain values were those that presented higher degree of isomorphic substitution of $\mathrm{Al}$ by $\mathrm{Fe}$ and, consequently, lower average crystallite size values. It is shows in Fig. 2. 


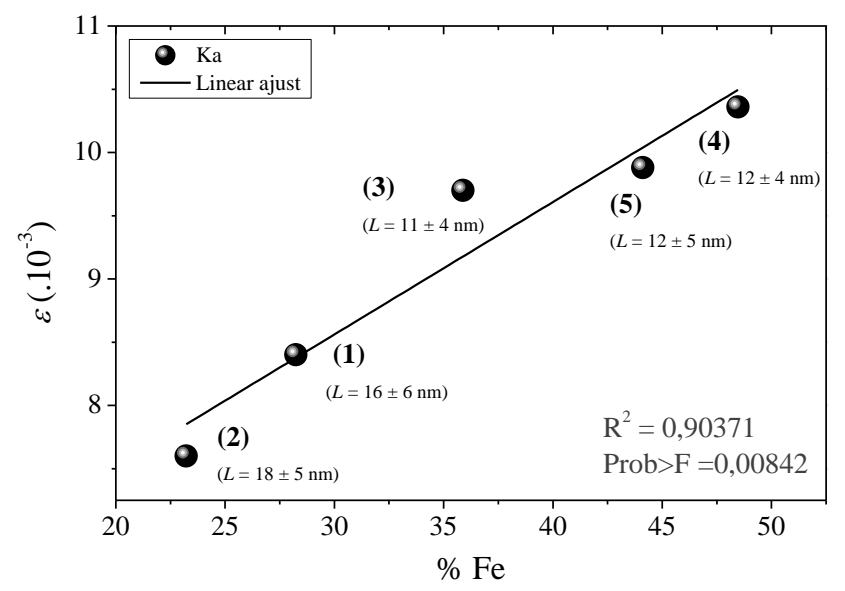

Fig. 2. Correlation between degree of isomorphic substitution and microstrain by percentage of $\mathrm{Fe}$ occupying the Ka.

\section{Conclusion}

Based on these results, it is possible to state that soils with higher degrees of isomorphic substitution and microstrain were submitted with higher intensity to the weathering process and probably corroborate with each soil hardness degree, due to the charge excess between the Kaolinite layers.

\section{REFERENCES}

[1] N. F. B. Giarola, H. V. Lima, R. E. Romero et al, "Crystallograpy and mineralogy of the clay fraction of hardsetting horizons in soils of Coastal Tablelands in Brazil," R. Bras. Ci. Solo, vol. 33, pp. 33-40, 2009.

[2] M. M. Corrêa, J. C. Ker, V. Barrón et al, "Characterizing iron oxides from coastal and central plain soils," R. Bras. Ci. Solo, vol. 32, pp. 1017-1031, 2008.

[3] G. W. Brindley, Chih-Chun Kao, J. L. Harrison et al, "Relation between the structural disorder and other characteristics of kaolinites and dickites", Clay Clay Miner, vol. 34, pp. 233-249, 1986.

[4] L. V. Prandel, S. C. Saab, A. M. Brinatti et al, "Mineralogical analysis of clays in hardsetting soil horizons by X-ray fluorescence and X-ray diffraction using Rietveld method," Radiat Phys Chem, vol. 95, pp. 6568, 2014.

[5] A. C. Larson, R. B. Von Dreele, "GSAS - General Structure Analysis System," Los Alamos: University of California, 2004.

[6] B. H. Toby, "EXPGUI, a graphical user interface for GSAS," J. Appl. Crystallogr., vol. 34, pp. 210-213, 2001.

[7] H. M. Rietveld, "A profile refinement method for nuclear and magnetic structures," J. Appl. Crystallogr., vol. 2, pp. 65-71, 1969.

[8] H. M. Rietveld, "Line profiles of neutron powder-diffraction peaks for structure refinement," Acta Crystallogr., vol. 22, pp. 151-152, 1967.

[9] R. A. Young, "The Rietveld Method," New York: Oxford University Press, 2002.

[10] R. T. Downs, Hall-Wallace, "M. American mineralogist crystal structure database," Am. Mineral., vol. 88, pp. 247-250, 1993.

[11] D. Balzar, N. C. Popa, "Analyzing microestructure by Rietveld refinement," The Rigaku Journal, vol. 22, pp. 16-25. 